\title{
Informes
}

\section{Noticias del Grupo Guatemala-México Migración y Desarrollo}

\section{Relatoría de Manuel Ángel Castillo*}

Los días 12 y 13 de febrero de 2004 se llevó a cabo en la Ciudad de México la Sexta Reunión del Grupo Guatemala-México Migración y Desarrollo. En esta ocasión el objetivo de la reunión fue la presentación - ante el gobierno y la sociedad mexicanos- del documento: "Las migraciones y el desarrollo entre Guatemala y México: una propuesta de elementos de política y acciones".

Dicho documento expone el resultado de 18 meses de trabajo del Grupo e integra, además de sus antecedentes y constitución, los diez principios y preceptos que, según sus miembros, deben regir los procesos migratorios en la región. Asimismo, propone tanto elementos de política como algunas acciones prioritarias que en materia de protección consular y de relaciones laborales entre ambos países, debieran adoptar sus respectivos gobiernos.

El Grupo es una iniciativa ciudadana, generada por medio de un proyecto impulsado por El Colegio de México, a través de su Centro de Estudios Demográficos y de Desarrollo Urbano, y la Facultad Latinoamericana de Ciencias Sociales (Flacso)-Sede Académica Guatemala, por medio de su Programa de Migración. Se integró con el propósito de elaborar una propuesta de lineamientos de política pública migratoria, para ser presentados y discutidos en esferas gubernamentales y sectores sociales y políticos interesados.

El Grupo está integrado por diecisiete personas, mujeres y hombres, provenientes de sectores diversos de las sociedades de ambos países e interesadas en que se considere la migración como una oportunidad para el desarrollo y el bienestar de ambos países. Sus actividades se han llevado a cabo gracias a los apoyos de la Fundación Ford, la Fundación soros y Catholic Relief Services.

Debido a la importancia que posee el fenómeno migratorio, en esta ocasión el texto fue presentado en reuniones realizadas con fun-

* Profesor-investigador del Centro de Estudios Demográficos y de Desarrollo Urbano de El Colegio de México. 
cionarios de las representaciones diplomáticas y consulares de países centroamericanos acreditadas en México; integrantes de la comunidad académica, especializados en las migraciones internacionales, las relaciones internacionales y los estudios fronterizos; miembros de organizaciones civiles; así como también con diversos medios de comunicación.

Entre los asistentes a estas reuniones puede mencionarse a representantes diplomáticos y consulares de Guatemala, El Salvador, Honduras y Costa Rica; investigadores de El Colegio de México, la Universidad Nacional Autónoma de México, el Centro de Investigación y Docencia Económicas y el Instituto Mora; miembros de la Fundación Solidaridad México-Americana, Sin Fronteras y el Servicio Jesuita a Migrantes, entre otros.

Durante esos días, el Grupo sostuvo entrevistas con funcionarios de la Secretaría de Relaciones Exteriores, la Comisión de Ayuda a Refugiados, el Consejo Nacional de Población, el Instituto Nacional de Migración, la Comisión Nacional de Derechos Humanos y la Comisión de Población y Desarrollo de la Cámara de Senadores. Se tienen previstas reuniones posteriores con el secretario de Gobernación, así como con el titular de la Secretaría de Trabajo y Previsión Social, entre otros. 